\title{
Using the resources framework to design, assess, and refine interventions on pressure in fluids
}

\author{
Daniel E. Young* \\ Department of Physics, Gustavus Adolphus College, Saint Peter, Minnesota 56082, USA \\ Dawn C. Meredith ${ }^{\dagger}$ \\ Department of Physics, University of New Hampshire, Durham, New Hampshire 03824, USA
}

(Received 27 July 2016; published 15 May 2017)

\begin{abstract}
The resources framework provides a useful and generative model of student thinking and learning. In particular, it suggests various strategies for instruction such as priming resources and refining intuition that allow students to build on knowledge they already have. In this paper, we describe the affordances of the resources framework in guiding the design, assessment, and refinement of interventions on pressure in fluids. This perspective kept us alert for cognitive resources on which students could build a deeper understanding and encouraged us to model student thinking as complex and context dependent, even on this narrow topic. This framework also facilitated a focus on evidence of productivity in student work as an alternative assessment to conceptual pre- and post testing.
\end{abstract}

DOI: 10.1103/PhysRevPhysEducRes.13.010125

\section{INTRODUCTION}

As curriculum developers and assessors of introductory physics materials, we look to the physics education research (PER) literature to give us guidance on how to model student thinking. The two frameworks that influence much PER work are the misconception and resource frameworks: they inform what we pay attention to in student thinking, how we scaffold student work, how we assess our success as instructors, and how we interact with students in the moment [1].

The misconceptions perspective is a framework used in designing activities, and focuses on carefully delineating student misconceptions and difficulties and employing elicit-confront-resolve strategies in the development of the interventions; curricula are assessed using pre- and postconceptual tests [2-4]. One concern with this approach is that the elicit-confront-resolve approach sends the undesirable epistemological message that students' everyday experiences are not valuable in the physics classroom [5] (p. 633). A second, implicit perspective is that described by Redish as "folk models" of thinking and learning [6], developed by instructors over years of experience teaching. However, these models "can lead us dramatically astray in trying to make sense of how our students are responding in our classes" [6] (p. 593). Because of these concerns, as we

\footnotetext{
*dyoung4@gustavus.edu

dawn.meredith@unh.edu
}

Published by the American Physical Society under the terms of the Creative Commons Attribution 3.0 License. Further distribution of this work must maintain attribution to the author $(s)$ and the published article's title, journal citation, and DOI. began our work on developing tutorials for the Introductory Physics Course for Life Science students (IPLS) on moving fluids, we chose instead to adopt the resources framework [7] as it provided us with three valuable perspectives that we outline here.

First, the resources framework asks us to pay attention to student thinking, as initial student ideas can provide a "way in" to student thinking, and allow them to make progress toward a normative understanding [8] by building on and refining what they already know. We will give evidence that life science students do have the cognitive resources they needed to reason productively about moving fluids.

Second, this framework models student thinking as context dependent and therefore complex and multifaceted $[7,9]$. Even though all of the student reasoning cited in this paper is on pressure and fluids, we found that student reasoning resources were different in different contexts. Being alert to this complexity is important for curriculum developers.

Third, the framework asks us to focus on productive student reasoning (that is, reasoning that indicates progress), rather than correct reasoning. This perspective encourages us to design interventions that are engaging and challenging and that give students an opportunity and the motivation to make progress. It also prevents us from interfering too early in a rush for students to "get it right."

Previous work has described the application of the resources framework to curriculum design [5,10-12]. We add to the existing resources framework literature by describing in detail how the resources perspective was used in every phase of designing, assessing, and refining interventions in the context of moving fluids, as these 
details may be of value to other curriculum developers. We used the literature and student interviews to find common student resources and designed the interventions to elicit and refine these resources. We expected students to need different resources in different contexts, even in the relatively narrow topic of pressure in fluids. We extended the ideas of productivity in the literature to define in-themoment productivity that can be recognized from short pieces of conversation or writing. This allowed us to assess our curricular interventions by looking for signs of productivity in student reasoning. Finally, we refined the interventions based on what we learned from our students.

We begin this paper with the motivation for creating interventions on moving fluids in Sec. II. We follow this with a review of the literature in Sec. III on student thinking about static fluids and the microscopic viewpoint of pressure in fluids. In Sec. IV we outline the resources framework and notions of productivity that guided our work. We then describe our instructional context (Sec. V) and how the resources framework guided the design of our interventions (Sec. VI). In Sec. VII we outline how the data were analyzed in this framework. In the last two sections of the paper, we present two data sets and show evidence of conceptual resources and productivity, and conclude with an assessment of the interventions.

\section{WHY MOVING FLUIDS?}

This work began when we made major changes in our Introductory Physics course for Life Science (IPLS) students [13]. Our reforms were initiated both by local concerns and by the calls of biology and medical professionals in national policy documents [14-16] for a rethinking of the undergraduate biology curriculum. Our work is part of nationwide efforts to increase the impact and value of this course for the students it serves [17-21].

As we reformed our course, it became clear that the topic of fluids needed more coverage than was typically given. Fluids are omnipresent, both inside and outside organisms, used for transport, communication, and structure [22,23] and yet often get cursory treatment in an introductory course. In addition, there was no PER research or curriculum development on moving fluids in any instructional context. With our colleagues at the University of New England [24], we set out to develop and assess tutorials around essential moving fluids topics, such as continuity, viscosity, Hagen-Poiseuille, and Bernoulli's principle. While these are our end goals, this paper focuses only on the initial tutorials. For reasons detailed in Sec. VI, these initial curricular materials focused on ideal gases, the kinetic theory of gases, and pressure; these subtopics are the single content focus of this paper.

\section{PREVIOUS RESEARCH ON STUDENT REASONING ABOUT FLUIDS AND PRESSURE}

While there have been no PER studies to date about student understanding of moving fluids (i.e., Bernoulli's principle, continuity equation, or viscosity), there is a substantial body of work on students' reasoning about static fluids, pressure, and the ideal gas law. As these latter ideas are fundamental for an understanding of moving fluids, we have found this literature valuable for our work on moving fluids and provide an overview of these studies here.

\section{A. Pressure and static fluids}

A series of studies by the University of Washington Physics Education Group focused on student understanding of static fluids and related topics: the ideal gas law [26,27] and volume of an ideal gas [28], buoyancy [2,3,29], and hydrostatic pressure [4]. While buoyancy was not directly applicable to our work, the ideal gas studies informed our perspective on microscopic versus macroscopic approaches (detailed in the next section), and tutorial development (Sec. VIII).

In the study on hydrostatic pressure, students were unable to correctly identify all of the forces acting on a sample of liquid, often missing the forces from the container. Loverude et al. [4] then developed an instructional sequence in which students practiced making free body diagrams and analyzing forces for several systems at rest, being sure to include both contact forces and gravity. Post-test results indicated that students' reasoning about static fluids significantly improved; more than $80 \%$ of the students who had completed the tutorial answered correctly on problems dealing with identifying pressure in a static fluid with correct reasoning. These articles alert us to the likelihood that unresolved difficulties with mechanics and forces will surface again in discussion of fluids. Or, viewed from another perspective, this work indicates that we can use the study of fluids as another opportunity for students to deepen their understanding of forces.

\section{B. Microscopic versus macroscopic perspectives}

One other theme that arises in discussion of liquids and ideal gases is microscopic versus macroscopic descriptions. We struggled to decide which approach to take, and the literature was essential in framing that decision.

The University of Washington studies on the ideal gas law $[26,27]$ examined student understanding of the ideal gas law from both the microscopic and macroscopic point of view. At the macroscopic level, students conflated ideas of heat, temperature, and internal energy and failed to understand the role of work. At the microscopic level, students sometimes attributed macroscopic properties (e.g., temperature) to a single molecule, and they struggled with mechanics concepts, such as the change of momentum due to collisions with a wall. The student difficulties that the researchers saw at the microscopic level led them to advise 
beginning instruction with macroscopic phenomena, and then moving to the microscopic level.

Robertson and Shaffer [28] further probed the connections between microscopic and macroscopic reasoning about a volume of an ideal gas. They found that "although students and teachers may appear to use the basic tenets of kinetic-molecular theory, they may not do so consistently." In particular, many students claimed that cold gas particles would not fill their container, thus showing some difficulty with the notion of volume from the molecular point of view.

Other work also documented students' lack of success with the microscopic point of view. Gillespie [30] investigated the details of student talk over a three week period about compression of a gas. She noted, "what I saw as a key theme in the curriculum, developing a particulate model of gas behavior, was routinely side-stepped by the students" (p. 242).

While these studies documented the students' failure to use the microscopic picture normatively, or in some cases even at all, there are also several examples of students reasoning correctly and productively with this microscopic point of view in other contexts.

Chabay and Sherwood [31] advocate for the microscopic point of view, which they use extensively in their text Matter and Interactions [32]. They argue that by using the microscopic or atomic point of view, students can integrate thermal physics and mechanics in a powerful way. They give several examples of how the microscopic picture provided students with deep understanding of challenging topics, including entropy: “...we observe that our students find these usually difficult concepts surprisingly accessible because the whole treatment is very concrete and explicit." They also see the value of being able to think about motions of atoms and molecules: "Because an atomic level model is often mentally 'runnable,' mechanistic causal reasoning is possible by mental simulation." Additionally, in chemistry courses, there is evidence that the particulate nature of matter is useful and productive for the students [33-37], and work on student understanding of microscopic friction also supports the value of this approach [38,39].

It is clear from the literature that reasoning about fluids is complex and that both the macroscopic and microscopic perspectives are possible entry points for students depending on the context. The resources framework allowed us to fully embrace this complexity (see Sec. IV). The literature opened our eyes to possibilities, but did not settle the question of how to design tutorials. We will discuss in Sec. VI how we decided on the microscopic perspective initially, and show in Sec. IX that it was not useful in all contexts. The data sections (Secs. VIII and IX) detail the complexity and variety of student thinking and illustrate the value of priming many different resources to help students reason in challenging situations.

\section{THEORETICAL PERSPECTIVES}

\section{A. Resources}

The resources framework introduced by Hammer [7] aligns with the constructivist theory that students must build their own knowledge. If we assert that students can (if properly scaffolded) build their own understanding, they must build it out of something that they already have. These "somethings" are cognitive resources: pieces of understanding that can be used to begin to make sense of new phenomena. Therefore students' naïve ideas are seen as the beginning of more normative ideas, in contrast to the misconceptions framework which sees students naïve ideas as barriers to learning [1].

To get a better idea of resources, several examples may be helpful. In work that was the progenitor of the resources framework, diSessa [40] gives evidence that a naïve "sense of mechanism" exists in our minds in the form of phenomenological primitives ( $p$ prims). These $p$ prims are resources that are relatively simple and are established and understood from common, everyday experiences. For example, closer means stronger is likely built from many experiences related to sound, light, and heat. Symbolic forms provide another example of resources essential in physics reasoning. Sherin [41] describes symbolic forms as the "conceptual vocabulary in terms of which physics equations are written and understood," which allow students to connect mathematics with their conceptual understanding of the phenomena. A simple example is the base plus change symbolic form.

Both $p$ prims and symbolic forms are types of conceptual resources but this does not exhaust the domain of resource types. There are also procedural (e.g., choose limits in an integration problem [42] and mechanistic reasoning [43]) and epistemological resources (e.g., knowledge as propagated stuff [10]). All of these play important roles in doing physics.

Work by Sabo, Goodhew, and Robertson [8] has shown how the resources perspective can be implemented in the classroom. They gathered data from 800 university students to find "recurrent, prevalent resources" about energy, and suggest that these resources (whether canonically correct or not) provide instructors "ways in" to their students' thinking. For example, students "associate forms of energy with indicators" such as change in position or movement. They therefore suggest that "indicators can link energy, an abstract concept, with students' concrete experiences and intuitions." The resources framework heightens instructor's attention to student ideas so that these are ideas are acknowledged and built on instead of being discarded.

In the remainder of this section, we define resources in more detail to allow us to identify resources in our students' speech and writing. We begin with the definition of Sayre and Wittmann [44] that resources are "individual reusable thoughts." "Individual" means that each resource is 
activated as a single unit and can be named and recognized by researchers through language or gestures. "Reusable" indicates that resources are unchanging and durable enough to be used multiple times.

While a student may have many resources tucked away in their head, not all of these resources are available to that student at all times. Harrer defines activation of a resource as "the conscious or unconscious recognition of applicability, as judged by the learner, and application of a resource to a certain situation" [43]. There is evidence that activation of resources is context dependent. Frank, Kanim, and Gomez [9] showed that the same question, posed differently, activated different resources. This context dependence can also be understood by a student's "framing" of the situation, that is, their understanding of "what is going on here?" $[6,45]$. For example, if a student views a problem as "plug and chug," they are unlikely to activate any of their sense-making resources. This lack of activation, however, does not mean they do not have sense-making resources.

The context dependence of resources implies that one role of an educator is to prime the activation of potentially useful resources that might otherwise remain dormant. Another role of an educator is to refine existing resources. An example of refinement of resources comes from Elby [10]. Students know that the less massive vehicle in a collision reacts more than the more massive one; the students then need to refine "reacts more" to "accelerates more," rather than "experiences more force."

Resources can be any grain size. Hammer [7] draws the analogy with computer programming: an experienced programmer can build a new program out of existing pieces of code of all sizes: lines, subroutines, and collections of subroutines. Similarly, resources can be small (closer is stronger) or quite complex (separation of variables [42]). Students may or may not be able to unpack the details of the resources they use. Last, resources are neither intrinsically correct nor incorrect, but are correct or incorrect in a given context. For example, the closer means stronger resource helps me understand why I want to get farther from the source of a loud noise, but it does not explain the relative warmth of the summer.

Researchers have access to activated resources through students' use of language [40,46] or gestures [47]. For example, in the use of symbolic forms, the phrases "balance" and "equilibrium" are clues that the balancing symbolic form is activated [41] (p. 533). In procedural resources used to evaluate an integral, the add constant resource is made manifest by those words [42]. For epistemological resources, the phrases similar to "Mommy told me" are evidence that the speaker is activating the knowledge as propagated stuff resource [10].

We end this section with examples of curricular interventions developed in the resources framework, and their relation to our work. Elby [48] and Redish and Hammer [5] describe the development of courses in which the thoughtful and frequent priming of epistemological resources helped students "learn how to learn physics." Redish and Kuo [11] and Redish [6] detail student thinking in several case studies and show how their responses are influenced by conceptual and epistemological resources, framing, and affect. Wittmann et al. [12] describe how they worked within the resources framework to design a tutorial on sound waves. Their goal was to prime students' existing resources related to events (rather than objects) in order to accurately describe sound waves, and also to promote the resources framework as a valuable pedagogical perspective. Our work builds on these previous works, and details the affordances in all stages of developing conceptual interventions.

\section{B. Productivity}

We now return to the key idea of productivity in the resources framework. Hammer notes that resources are seen as "productive aspects of student knowledge and reasoning, the raw material from which they may construct a physicist's understanding" [7] (p. S58), and not obstacles to student learning. In this section we look at several aspects of productivity and conclude with an operational definition of in-the-moment productivity.

Hammer notes that productive resources need not lead directly to a normative understanding, the activation need not be "appropriate." He states, "wrong' thinking should be seen as productive if it helps develop resources for later 'right' thinking" (p. S58). In assessing our curriculum and students' understanding, we wanted a similar broader sense of productive that valued reasoning that was not normative and yet was a step in that direction.

Just such a broader sense of productivity was developed by Russ, Hammer, and colleagues [49], who proposed looking for mechanistic reasoning in student conversation: "our purpose here is to analyze reasoning as mechanistic independent of its correctness" (p. 24) and developed "a systematic analysis of when and how students are invoking that sense or making progress developing it." Their goal was to examine student conversation in inquiry classrooms to look for signs of progress, noting that "both historically and for students, progress in scientific inquiry is characterized in part by a shift toward reasoning about causal mechanisms" (p. 2). They qualified their claims, noting that mechanistic reasoning is not the only valuable lens for examining student discourse.

Russ et al. defined nine aspects of mechanistic reasoning based on mechanistic reasoning in professional science. The first aspect is identifying the target phenomena itself. The next five aspects are related to identifying key features of the phenomena: setup conditions, entities, activities of entities, properties of entities, and spatial organization. The last three aspects are reasoning strategies: chaining, analogies, and animated models. They define chaining as, "by knowing the general properties of entities and activities, 
much can be said about what must have produced them at earlier stages and what they can produce in subsequent steps" (p. 12). Notably, the final category of animated models allows some relief from cognitive overload in thinking about complicated processes (this echoes one reason why Chabay and Sherwood [31] value microscopic models for students).

To illuminate these aspects, Russ et al. examined the conversation in a first grade class about falling objects. Student Brianna exhibited chaining by making the argument that crumpling a paper (activity) does not change its size (entity property) and therefore its weight is also unchanged. This helped the class agree that it was not the property of heaviness that made the crumpled paper fall faster than the uncrumpled paper.

In addition to reasoning mechanistically there are several other works that focus on productivity. Engle and Conant [50] discuss how to promote productive disciplinary engagement, and define productivity as "get[ing] somewhere" (p. 403). This could include "recognizing a confusion, making a new connection among ideas, or designing something to satisfy a goal." Two recent studies [46,51] have made strong claims about the productivity of resources about energy that are judged non-normative. Because their studies observe the same students over several days, they can judge productivity based on students making "significant progress" toward normative understanding.

With this background, we propose an operational definition of in-the-moment productivity that allows us to make a judgment of productivity based on short (minutes long) periods of talk and therefore to assess individual pieces of single tutorials. With our focus on conversation during a single lab session, we may not see either significant progress or normative thinking, and so we need a different definition of productivity.

We list in Table I several observable behavioral indications of in-the-moment productivity; this is not an exhaustive list. The first three are based on Russ et al; the last three expand on the notion of getting somewhere. For example, "real world connections" and "conceptual connections" are two of the categories on the Colorado Learning Attitudes about Science Survey that are seen as important to student learning [52]. Recognizing confusions or inconsistencies is an indication that students are looking for sense making, consistency, and coherence. These are epistemological

TABLE I. Signs of in-the-moment productivity.

Mechanistic chaining built on entities and their activities or properties

Constructing analogies

Running animated models

Connecting to existing knowledge

Noticing confusions or inconsistencies

Resolving confusions or inconsistencies stances that have shown to improve learning [53]. If recognizing confusions or inconsistencies is productive, then resolving these must be as well.

There are other uses for the notion of productivity. We will also show in Sec. IX that we can see some of these indicators in written work, and so can see productivity there as well. In-the-moment productivity also gives instructors another lens (besides textbook correctness) for deciding when and how to intervene in student discussion [54].

Looking for signs of in-the-moment productivity is a valuable assessment that can be used instead of or in addition to conceptual pretesting and post testing. This approach offers several benefits. First, there is the pragmatic issue that some topics (e.g., moving fluids) lack valid and reliable conceptual assessments. Second, looking for signs of productivity focuses our attention on student thinking and resource activation, and gives us direct insight into how to refine the interventions. Last, the literature gives evidence that we should interpret the results of conceptual surveys with some caution $[45,55,56]$.

This theoretical background motivates our central research questions: What resources do students use as they reason about ideal gases given our initial primed resources? What evidence do we have for productive work? How do these observations help us assess and refine our interventions?

\section{INSTRUCTIONAL CONTEXT}

Our target audience for the development of tutorials on moving fluids is our two-semester Introductory Physics for Life Science Students (IPLS) course. This is an algebrabased course, offered to 250-350 students each year. The vast majority (over 85\%) of these students are in the College of Life Sciences and Agriculture. Nearly all students need to take this course as a requirement for graduate programs for pre-health professionals or for their major. The students have a range of physics background, from no prior physics courses (25\%), to AP or college level physics (10\%). While $75 \%$ have taken a semester of calculus in college, $18 \%$ reported that they struggled with the mathematics in the class. This course had been reformed to be more in line with the needs of the life science students [13].

We took data from two different cohorts of students. The first group $(N=50)$ took a fast paced (5 week) summer course in 2013. This class had a studio format, meeting four days a week for a total of 10 hours each week. Lecture, lab, and group work were spread throughout the meeting time. The ideal gas law and the motion of fluid up a single straw were introduced through an interactive lecture with clicker questions. The data collected from these students were answers to the double straw question given in Table VII.

The second group of students $(N=300)$ took the first semester of this course during fall 2013. The course has three 50 min lectures and one 2 hour lab section each week. In some of the weeks, the lab time was used for problem 
TABLE II. Changing gas question and solution.

Question A: Ideal gas molecules exert pressure on their containers by colliding with the walls of the container (just as the bouncy balls collided with the beach ball). Increasing the strength of the collisions and the frequency of the collisions will increase the pressure on the walls... If we have a chamber with 10 oxygen molecules and we replace them with 10 hydrogen molecules [keeping temperature and volume the same], the frequency of the collisions will (increase, decrease, or remain the same), the strength of the collisions will (increase, decrease, or stay the same), and therefore the pressure in the chamber will (increase, decrease, or remain the same).

Question B: Consider the following conversation between two students who have also been working through the ideal gas law worksheet: Nathan: "If we have two containers where everything is the same (volume, temperature, and number of particles) but one is hydrogen and one is oxygen, the pressure in the hydrogen case must be smaller because they are lighter." Robert: "But wait! The ideal gas law says the pressure is the same $(P=n R T / V)$. But something must be different if the masses are different..." Do you agree with Nathan, Robert, or neither? How can you make their reasoning more complete based on your previous answers?

Possible normative response: If mass decreases and temperature is the same, velocity and therefore the frequency of collisions increases. We cannot tell if the strength of collisions increases, decreases, or stays the same because it depends on mass (which decreases) and velocity (which increases). But from the ideal gas law, we know that pressure remains the same so since frequency goes up, the collisional strength must go down in equal amounts in order to give the same pressure.

solving or paper and pencil tutorials, including those that we wrote and tested as part of this study. These students went through our tutorials on the ideal gas law [57]. The data collected from these students were answers to the changing gas question given in Table II.

\section{DEVELOPMENT OF TUTORIALS}

The resources framework guided our tutorial development, as we constantly looked for "ways in" [8] to student thinking, that is, for conceptual resources on which to build.

For example, our initial goal was to write tutorials on Bernoulli's principle and viscosity. However, we quickly realized that pressure and vacuums were difficult topics for our students, and needed to be addressed before moving to more challenging topics. Our first decision was whether or not to use a microscopic approach, which the literature showed gave mixed results (see Sec. III). This decision was informed by the work of our collaborators at the University of New England who found that a microscopic approach to understanding pressure and vacuums resulted in significant learning gains [24]. Their intervention was concrete and kinesthetic: small balls (representing gas molecules) were tossed at a large beach ball (representing a slice of fluid). First small balls were tossed equally from both sides, and then only from one side to mimic the effect of a vacuum and prime the idea the pressure is a push as opposed to a pull. Their success led us to adopt a microscopic approach (where feasible) as students constructed their understanding of fluids. When using the microscopic approach for the ideal gas law, we measured large gains in our own students' understanding of vacuums [58].

Next we decided to begin our study of fluids with the ideal gas law and the kinetic theory of gases. Early interviews and pretests, as well as the literature, showed that students understood this model in cases of standard temperature and pressure, although they had difficulties in more complex situations. It also allowed us to introduce microscopic ideas in a familiar situation.

As we developed tutorials we primed resources that we had heard students use in early interviews or which we felt were likely commonly used resources. We will discuss in Secs. VIII and IX what resources we primed and show that students did activate many resources that were part of productive discussions, some that we anticipated, and others that we did not. We will also show that the resources activated in the two problems were very different, even though both questions focused on pressure in fluids. The tutorials that we developed cover the ideal gas law, the nature of vacuums, the continuity equation, and Bernoulli's equation.

\section{METHODOLOGY}

We analyzed both videos of student work in labs and written work. Details of the data are in the following sections. To identify student resources, we analyzed subsets of the videos of students working through the tutorials, as well as student responses to open-ended problems. The analysis of conceptual resources was guided by grounded theory, a methodological approach to repeatedly analyze data and establish reliability and validity across researchers and contexts $[59,60]$. Since our methodology did not include all aspects of grounded theory, we characterize our methodology as a grounded approach.

A primary strategy of grounded theory method to extract meaning from data is open coding. In the process of open coding, researchers look at the data to create initial categories or concepts of interest. In our case, the categories were resources that students used to reason about moving fluids and signs of productivity. This is referred to as "open coding" because the categories are not decided a priori. We deviated from grounded theory because we did have the productivity codes and some resources as a priori categories, but we were also open to coding for unanticipated resources. 
We assume that if a resource is activated it will be manifested through language and thereby become accessible for study. Returning to Sayre and Wittmann's [44] definition of a resource as an "individual reusable idea," we claim an idea to be "reusable" if it is used by multiple students or one student multiple times. To claim "individuality," we require that resource candidates do not always appear with other ideas, or that the ideas appear in different orders for different students [42], which indicate that these resources are independent. Last, resources can be named by researchers [44] since they can be held in the mind as one idea even though they may have complex structure. Some resources (such as symbolic forms) have been identified in other work, and in these cases we rely on the earlier work for identification.

The main evidence of productivity in our videos is mechanistic chaining from Russ et al. Mechanistic chaining must begin with identifying entities and their activities and properties. This identification was not so difficult in the changing gas question (Table II) where key entities (gas and walls), properties (forces), and activities (collisions) were identified for the students. However, in the double straw question (Table VII) which was far less scaffolded, the students needed to make these identifications themselves. Once these entities, activities, and properties are identified, we recognize a chain as some variation of the form "because A then B," where "because" gives a reason why things happen. This is not merely correlation (e.g., the left turn arrow becomes green because cars are in the turn lane), but gives an explanation (e.g., cars in the left turn lane alter the inductance of a coil imbedded in the road, this is measured by a circuit, and sends a signal to the light to change [61]).

To ensure that the researchers who were examining the data were coding the student responses in the same manner, we choose to use a Cohen's kappa measure of qualitative inter rater reliability [62]. This requires that all coded data fall into one of two or more categories (e.g., "chaining" and "not chaining"), and takes into account the fact that the coding could be the same by chance. The kappa value is interpreted as follows: 0.21 to 0.4 is fair, 0.41 to 0.6 is moderate, 0.61 to 0.8 is substantial, 0.81 to 1 is almost perfect [62]. Our initial pass at the coding agreement generated a Cohen's kappa value which indicated fair to moderate interrater reliability (e.g., 0.31 for identifying chaining and 0.51 for identifying phenomenological primitives). After this initial training session and discussion, our Cohen's kappa values on a new data set were 0.72 for identifying chaining and 0.79 for identifying phenomenological primitives, indicating substantial interrater reliability.

In the following sections, we describe two different data sets where we apply this methodology to infer the activation of conceptual resources and claim in-the-moment productivity. We begin each section with a short discussion of how we designed the intervention to elicit productive conversation, describe the sources of data, and present a subset of the data and the analysis.

\section{CHANGING GAS TYPE}

\section{A. Goals and primed resources}

One main goal of the ideal gas law (IGL) tutorial is to deepen students' mechanistic understanding of the law; that is, why does pressure increase with temperature and number but decrease with volume? In the tutorial, we primed the use of the microscopic model by having students think about the frequency and strength [63] of collisions, first with beach balls and then with molecules. Using this idea of collisions, students found it straightforward to chain that increased temperature meant increased velocity, increased frequency of collisions, increased strength of collisions, and therefore increased pressure.

However, one of our IGL questions was not so straightforward: how does pressure change when the gas changes from oxygen to hydrogen while keeping temperature, volume, and number the same? This question was derived from the question of Kautz et al. [27] who asked students to compare the number of molecules of hydrogen and oxygen in two tanks of the same volume, temperature, and pressure. The students' responses in this earlier study almost always stated that there were more hydrogen molecules. From this they concluded that "we believe that many of these students had an intuitive feeling that there should be fewer molecules of the heavier species and that the algebraic manipulation was merely used to justify this preconceived response."

We infer from these data that the students had the idea that the mass should matter in this situation: if the pressure remained the same and the mass increased, the number of molecules had to be smaller. This is the compensation resource: if several quantities combine to give a constant amount, if one increases the other must decrease [64]. We designed the tutorial to give students an opportunity to refine [10] their intuition in this context (Table II). They were asked how changing gas type affected collisions, and then were presented with a conflicting contentions task to help them come to conclusion. The normative chain is reasonably complex; see Table II for details.

\section{B. Data}

The data analyzed for the ideal gas law were 11 videotapes from Fall 2013. Students were recruited in lab section for videotaping, which was an opt-in decision. All eleven videotapes were transcribed and coded for conceptual resources and in-the-moment productivity. As expected, the changing gas question was challenging for the students; each of the groups worked through the problem in a unique and usually detailed manner. 
TABLE III. Evidence for resources used in the changing gas problem.

\begin{tabular}{|c|c|}
\hline Resources & Phrases coded as indicating activation of this resource \\
\hline $\begin{array}{l}\text { Ideal gas law, no dependence } \\
\text { and identity symbolic forms }\end{array}$ & $\begin{array}{l}\text { "But [the mass] doesn't factor into the [ideal gas law] at all cause we're not changing } \\
\text { the variables in the pressure equation." } \\
\text { "Well I know if you change the type of gas the pressure is the same, right? } P V=N R T \ldots \\
\text { everything is the same so P is the same." } \\
\text { " } P V=N R T \text {, everything is gonna be equal if the moles are equal because volume, } \\
\text { temperature, etc. are equal. Ok so we agree with Robert right? Everything else } \\
\text { being equal, the pressure will be equal too." }\end{array}$ \\
\hline Lighter is faster or heavier is slower & $\begin{array}{l}\text { "Since it is lighter it ...will it travel faster since it's lighter?" } \\
\text { "The one that has a larger mass is going to have a smaller velocity." }\end{array}$ \\
\hline$K E=(1 / 2) m v^{2}$ and compensation & $\begin{array}{l}\text { "The mass did go down...but their kinetic energy is still the same so that means } \\
\text { their velocity went up." } \\
\text { "[Helium] won't have more kinetic energy, it will be the same but it will be, like, higher } \\
\text { velocity because the mass decreases." } \\
\text { "...velocity wouldn't be the same because they're different masses. KE equals } \\
\text { one-half M velocity squared. So if they have a different mass they must have a } \\
\text { different velocity because the kinetic energies must be equal." }\end{array}$ \\
\hline Compensation & $\begin{array}{l}\text { "The frequency of the collisions will be more with helium cause they're moving faster. } \\
\text { The strength then has to decrease to give a net of zero change." } \\
\text { "So because it's moving faster and hitting more often, its mass is doing less on } \\
\text { each impact so the strength is decreased but because the frequency is increased...they } \\
\text { equal each other." }\end{array}$ \\
\hline
\end{tabular}

We identified resources using the methodology outlined in Sec. VII. In Table III we provide a list of the most commonly identified resources as the students were working through the changing gas problem, along with evidence from the transcripts that supports those identifications. None of the resources mentioned always appeared with any other resource, hence we claim individuality.

The ideal gas law was a common resource for the students and the students' use of this was clear, by either naming or saying the equation. Some groups introduced the idea themselves; others were prompted by the conflicting contentions task. This law was then often used with the no dependence symbolic form, as seen by the phrase "doesn't factor into" in the first table entry. It was also used with the identity symbolic form, which Sherin defines as "anything true of the expression on the right is true of the individual symbol on the left" [41] (p. 536). This is seen in the second and third quotes, where the students noted that every term aside from pressure in IGL is the same, so the pressure is the same.

In the second row of Table III we see examples of lighter is faster and heavier is slower [65], where students used almost those exact phrases. These resources are correctly applied in the case of constant temperature. In the third row, the students came to this same conclusion using two resources: the equation for kinetic energy (referenced explicitly by each student) and the compensation resource. The compensation resource is seen in noting two initial facts (KE are equal, mass goes down) and concluding the velocity goes up. All but one group used either the lighter is faster resource, or a KE plus compensation set of resources. The compensation resource is identified when students remark on one quantity increasing, therefore another is decreasing to keep their quantity constant. This then led reliably to the conclusion that the velocity and therefore frequency of collisions increased when the mass decreased.

While these were the most common resources that we identified, the full list of all identified resources in the changing gas problem is listed in Table IV.

One key missing resource for many of these groups was that the strength (i.e., the impulse or change of momentum) of the collisions is proportional to mass times velocity. (We note that many students talked about force or energy of collisions in place of strength, though they never connected this with a complete mathematical formula in this context.) The preceding section in the tutorial asks students to consider what variables affected the force [63] of collision

TABLE IV. Resources used in the changing gas problem.

Lighter is faster

Heavier is slower

Symbolic forms (dependence, nondependence, identity)

More is more (more velocity implies more collisions)

Less is less (less mass implies less collisional strength)

Ideal gas law

$K E=(1 / 2) m v^{2}$

Temperature $\sim K E$ 
TABLE V. Changing gas conversation A.

\begin{tabular}{|c|c|c|}
\hline Dialog & Conceptual resources & Evidence of productivity \\
\hline $\begin{array}{l}\text { Adam: The gas molecules are traveling faster because their energy } \\
\text { is the same so....that means that, wait...no yeah, their velocity } \\
\text { should increase. } \\
\text { Beth: Because the mass goes down? }\end{array}$ & Compensation & Chaining \\
\hline $\begin{array}{l}\text { Adam: Yeah, so they are moving faster and colliding with the walls } \\
\text { more so...does the force or frequency increase? Probably the } \\
\text { frequency right? }\end{array}$ & $\begin{array}{l}\text { More velocity means more } \\
\text { collisions }\end{array}$ & Noticing confusions \\
\hline $\begin{array}{l}\text { Chris: Yeah frequency goes up but force goes down because they } \\
\text { weigh less. }\end{array}$ & $\begin{array}{l}\text { Less mass means less force } \\
\text { More velocity means more } \\
\text { collisions }\end{array}$ & Chaining \\
\hline $\begin{array}{l}\text { Adam: So does the pressure go up or down? Which one matters } \\
\text { more? }\end{array}$ & Dependence symbolic form & Noticing confusions \\
\hline $\begin{array}{l}\text { Beth: Maybe the force matters more because isn't pressure a force? } \\
\text { Wait though...the ideal gas law says that the pressure has to stay } \\
\text { the same, does that make sense? }\end{array}$ & $\begin{array}{l}\text { Ideal gas law } \\
\text { No dependence }\end{array}$ & Noticing confusions \\
\hline $\begin{array}{l}\text { Chris: I guess that means that the two will be equal, force goes } \\
\text { down but they hit more often which I guess is a balance. }\end{array}$ & Compensation & Chaining \\
\hline
\end{tabular}

of beach balls, and we had expected that they would note that both velocity and mass matter. Unfortunately, the conclusion that both the velocity and mass are relevant was not reached as reliably as we had expected. However, once the ideal gas law resource was introduced into the conversation (either by the conflicting contention task or unprompted by the students), the conversation progressed forward rapidly.

In Table $\mathrm{V}$ we see how one group reasoned through this problem. There is chaining or recognizing confusions in every turn of conversation. Chaining is identified when students go from properties of entities to other properties of

TABLE VI. Changing gas conversation B.

\begin{tabular}{|c|c|c|}
\hline Dialog & Resources & Evidence of productivity \\
\hline $\begin{array}{l}\text { Alex: But like, } P V=N K_{b} T \text { doesn't have a mass in there, doesn't have } \\
\text { size in there. } \\
\text { Chelsea: Right, but you can separate gases by their weight so, how does } \\
\text { that work then? }\end{array}$ & $\begin{array}{l}\text { No dependence } \\
\text { symbolic form }\end{array}$ & \\
\hline $\begin{array}{l}\text { Alex: I think it does what I think it is, is if you use the formula for kinetic } \\
\text { energy and we have the same kinetic energy going on 'cause it's the } \\
\text { same system, then the mass increased, which means that the velocity } \\
\text { decreased. Its got that sort of relationship with each other. Size increase, } \\
\text { velocity decrease, less hits against the sides of the container. }\end{array}$ & $\begin{array}{l}K E=(1 / 2) m v^{2} \\
\text { Compensation } \\
\text { Less velocity means } \\
\quad \text { fewer collisions }\end{array}$ & Chaining \\
\hline $\begin{array}{l}\text { Patrick: I'm trying to picture it, a container with helium and a container of } \\
\text { argon. It doesn't have anything to do with moles? }\end{array}$ & & $\begin{array}{l}\text { Running animated } \\
\text { models }\end{array}$ \\
\hline $\begin{array}{l}\text { Alex: } P V=N R T \text {, everything is gonna be equal if the moles are equal } \\
\text { because volume, temperature, etc., are equal. Ok so we agree with } \\
\text { Robert right? Everything else being equal, the pressure will be equal } \\
\text { too. So if temperature, volume, constant, and number of particles are } \\
\text { the same for two different systems then the pressure has to be the same } \\
\text { for those two systems. }\end{array}$ & $\begin{array}{l}\text { Identity symbolic form } \\
\text { Ideal gas law }\end{array}$ & \\
\hline Chelsea: So are their kinetic energies different? & & Noticing confusions \\
\hline $\begin{array}{l}\text { Patrick: No, their kinetic energies have to be the same, but their velocities } \\
\text { are going to be different and velocity isn't included in } P V=N R T \text {. The } \\
\text { one that has a larger mass is going to have a smaller velocity, that's how } \\
\text { the kinetic energies will be equal. }\end{array}$ & $\begin{array}{l}\text { Compensation } \\
\text { No dependence } \\
\text { symbolic form }\end{array}$ & \\
\hline
\end{tabular}


entities. For example, Adam uses properties of entities (same energy, decreased mass) to conclude increased velocity (another property of the helium). There are also two key times when confusions are noticed: Adam asks both "does the force or frequency increase?" and "So does the pressure go up or down? Which one matters more?" and these confusions are addressed in the next turns of conversation.

They used several conceptual resources, which are also listed in Table V. Two confusions were noted, raising issues of what is more important in changing the pressure. Once the ideal gas law was introduced, they were able to see that compensation resolved the confusion. This conversation was mechanistic because it focused on entities (gas molecules) and properties of entities (velocity and mass), though we remind the reader that these were identified for the students. Also, the conversation indicates several instances of chaining ideas together, which makes this mechanistic and, therefore, in-the-moment productive.

In Table VI we see a slightly different approach to the problem. This group saw that there is increased velocity which changes the frequency of hits; this conclusion was reached reliably for all groups. But they did not consider what happens to the strength of collisions and rely solely on the ideal gas law to reach their conclusion. Their reasoning appears to be half mechanistic because they consider the frequency but not the strength and so did not explain how pressure can stay the same based solely on entities and their properties. Similarly, Russ [54] notes that use of the mathematical model given by the IGL is not mechanistic, but causal.

In summary, all groups used the no-dependence or identity symbolic form to read off of the ideal gas law that changing the mass or velocity (at constant temperature) had no effect on the pressure. About two-thirds of the videotaped groups used a fully mechanistic account (similar to Table V), using the IGL to break the tie between increased frequency and decreased strength of collisions to conclude that pressure remained the same.

\section{Assessment of intervention}

Overall, we were impressed with student discussions on this topic, and saw evidence of in-the-moment productivity. They were chaining (although sometimes the links in the chains were not completely substantiated, e.g., they inferred that since mass decreases, strength decreases-ignoring dependence on velocity), they connected their answers to the ideal gas law which was introduced in the conflicting contentions task, and they acknowledged and resolved conflicts between their answer and the ideal gas law. While all groups did end with the conclusion that we anticipated (thanks to the authority of the ideal gas law), not all groups provided a mechanistic explanation based on collisions.

Students productively used several different conceptual resources in reasoning about this problem. The nodependence symbolic form was key to understanding, since decrease of mass and increase in velocity meant that the change in strength of collision was indeterminate, and therefore the lack of a mass term in the ideal gas law was essential. The compensation resource allowed students to have a mechanistic understanding of constant pressure: when mass decreases the frequency of collisions increases and the strength of collisions decreases. This offers students a way to reconcile how changing mass does change some features of the system without changing the pressure.

Based on these data, we conclude that this is a good start to the tutorial question. It could be improved by further scaffolding the discussion about the strength of collisions being dependent on both velocity and mass. Also, a checkin with the teaching assistant, a full class discussion, or homework is likely needed to review these concepts once again, given that the chain is long and not intuitively obvious. Because a compensation argument is being used, numerical values are valuable to deciding the dependence of pressure on the change in mass. One quick calculation with simple numbers could allow students to see that if mass goes down by a factor of 4 , velocity goes up by a factor of 2, and so the strength of collision does indeed decrease and pressure stays the same.

In these questions, we scaffolded student thinking by asking about frequency and strength of collisions. We also primed resources related to familiar experience of collisions. We felt this was necessary in order to think about the difficult case of changing gas type, given the known student difficulties [27]. However, priming certain resources does not guarantee that students will use them. In an question earlier in the tutorial on the effect of gravity, we asked questions to lead to the conclusion that gravitational potential energy was negligibly small for gases in "normal" ranges (e.g., -20 to $20^{\circ} \mathrm{C}$ ), to prime the notion of "inconsequential." Unfortunately, students saw this as a recursive plug and chug problem [66] and did not make sense of what they were doing.

TABLE VII. Double straw question and solution.

When you drink with two straws (one in and one out of water) no liquid comes up the straw. Why?

Possible normative response: By inhaling we create a partial vacuum at the top of the straw. This results in a pressure gradient in both straws, and a net force upward (even though gravity is acting downward), and an upward acceleration. The pressure gradient is the same on the water and the air, the net upward force on the air is greater (due to smaller weight acting downward), and because air in the straw is lighter than the water in the straw it will accelerate faster and will make it up the straw before the water. This then makes the pressure in the mouth equal to atmospheric pressure, there is no more pressure gradient, no net force upward, no acceleration, and no motion of the water upward. 
TABLE VIII. Evidence for resources for double straw problem.

\begin{tabular}{|c|c|}
\hline Resource & Phrases coded as indicating activation of this resource \\
\hline $\begin{array}{l}\text { No pressure difference results } \\
\text { in no motion }\end{array}$ & $\begin{array}{l}\text { "...because the pressure in your mouth is equal to the atmospheric pressure. When pressures are } \\
\text { equal no movement happens." } \\
\text { "...therefore the air pressure in your mouth is equal to the air pressure outside and no liquid is } \\
\text { pushed up the straw and into your mouth." } \\
\text { "The water won't go up the straw because there is not a pressure difference so the atmospheric } \\
\text { pressure won't force the water up." }\end{array}$ \\
\hline Open systems are not vacuums & $\begin{array}{l}\text { "...it's because the straw that is not in the liquid that is exposed to the air changed the pressure in } \\
\text { your mouth to atmospheric pressure causing it to be unable to suck up any liquid because its not a } \\
\text { vacuum so it doesn't work." } \\
\text { "...b/c there is no vacuum force b/c the other end isn't closed completely." } \\
\text { "... as there isn't a seal to create the vacuum." }\end{array}$ \\
\hline $\begin{array}{l}\text { Pressure differences result } \\
\text { in motion }\end{array}$ & $\begin{array}{l}\text { "If the pressure in the mouth was less then the pressure at the bottom of the straw then the liquid } \\
\text { would be able to go up the straw..." } \\
\text { "In order to drink water from a straw, you decrease the pressure inside the straw by sucking up the } \\
\text { air, and atmospheric pressure pushes the rest of the water in the glass up the straw." } \\
\text { "In the diagram [with one straw] the water is able to be sucked up the straw because you are } \\
\text { decreasing the pressure pushing down in the straw so the water is able to move up." }\end{array}$ \\
\hline
\end{tabular}

\section{DOUBLE STRAW}

\section{A. Goals and primed resources}

An important idea in the study of fluids is the understanding that pressure differences result in a force which must be considered with all other forces to infer changes in velocity. Considering motion of liquid up a single straw provides a simple application of this idea.

The intervention studied in this section is the double straw problem (see Table VII). The idea we expected students to use was the mechanistic understanding of how fluid moves up a single straw. The double straw question problematizes the idea that you can bring fluid up a straw by inhaling, since in the two straw situation liquid does not move up the straw, so we expected this would be an engaging problem [50].

\section{B. Data}

The ideas for a single straw were discussed as part of a peer instruction question during class of summer 2013. The double straw question was an optional question on homework for that class; 32 out of 50 students answered this question. Students were allowed to opt out of having their written work included in the study, but none did so. Because the students self-selected to answer this question, we can conclude nothing about the students who did not answer this question. In fact, since this was labeled as a difficult problem, it is likely that the students who did not answer would have struggled more than those who did answer.

Our initial impressions are that students did engage with this problem. These impressions were based on the wide variety of answers and the detailed nature of the answers we received. We then followed up these impressions with identifications of resources and signs of in-the-moment productivity.

We identified several resources used by students, based on the heuristics outlined in the Sec. VII. In Table VIII, we list the three most commonly used resources, and give several quotes from students who used that resource. None of the listed resources always appeared with another resource, hence we claim independence and individuality of these resources. We were also able to name the resources, indicating that they are single cognitive units, although likely with internal structure.

While the exact words used by students are different, the meaning is quite similar. For example, the notion of "open" was variously expressed as "exposed to the air," "isn't completely closed," and "there isn't a seal." The idea of "no vacuum" was also expressed as "atmospheric pressure."

The full list of resources that we saw used by at least three students are shown in Table IX. Many of the resources were expected, since they were used in the single straw case, and therefore indirectly primed by the similar context. The "open systems are not vacuums" resource was not used (or needed) in the context of the single straw. However, this resource was used throughout the text [67] and in lectures,

TABLE IX. Resources used in double straw problem.

Open systems are not vacuums

No pressure differences results in no motion

Pressure differences result in motion

Sucking creates a vacuum

If air is present there is no vacuum

Vacuums create pressure differences

No vacuum results in no motion

Lighter is faster 
TABLE X. Student answers to the double straw question.

\begin{tabular}{|c|c|c|}
\hline Answers & Resources & Evidence of productivity \\
\hline $\begin{array}{l}\text { Ari: This is because the straw on the outside of the drink is sucking } \\
\text { up air, equalizing the pressure inside your mouth with that } \\
\text { outside, not allowing the liquid to be pushed up the straw. }\end{array}$ & $\begin{array}{l}\text { No pressure gradient results in } \\
\text { no motion. } \\
\text { If air is present there is no } \\
\text { vacuum }\end{array}$ & Chaining \\
\hline $\begin{array}{l}\text { Sarah: If you tried to suck up the water through the } 2 \text { straws, little to } \\
\text { no water would travel up the straw. If you thought of your mouth } \\
\text { as a box, you would notice that the box (mouth) would not } \\
\text { become a vacuum for either of the tubes (straws) because only } \\
\text { one of them contains a liquid, the other is open, leaving the } \\
\text { whole system open with no vacuum. }\end{array}$ & $\begin{array}{l}\text { Open systems are not vacuums } \\
\text { Vacuum creates motion in a } \\
\text { straw }\end{array}$ & $\begin{array}{l}\text { Analogy with a box } \\
\text { Chaining }\end{array}$ \\
\hline $\begin{array}{l}\text { Andy: Because the vacuum you are creating pulls the air up the } \\
\text { straw not in the drink because it has a lower density than the } \\
\text { liquid and more easily is pulled up the straw. }\end{array}$ & $\begin{array}{l}\text { Lighter is faster } \\
\text { Vacuum creates motion in } \\
\text { straw }\end{array}$ & Chaining \\
\hline $\begin{array}{l}\text { Jill: The liquid will not go up the straw that is under the water. This } \\
\text { is because the pressure in the straw in the liquid is greater than } \\
\text { the straw in the air so when you try to drink the straw in air will } \\
\text { be the only one to take in anything since there is no pressure. } \\
\text { Like a vacuum. }\end{array}$ & $\begin{array}{l}\text { Vacuums create motion in } \\
\text { straws }\end{array}$ & Chaining \\
\hline $\begin{array}{l}\text { Mary: Liquid moves up the straw in a normal situation because the } \\
\text { pressure in your mouth is less than that of the liquid, causing the } \\
\text { liquid to move into the lower pressure region. If a second straw } \\
\text { open to the atmosphere is added, it eliminates the ability to create } \\
\text { a vacuum because of the interference of atmospheric pressure, as } \\
\text { this pressure is now being applied to the mouth (effectively } \\
\text { eliminating its vacuum function). }\end{array}$ & $\begin{array}{l}\text { Pressure gradient causes } \\
\text { motion } \\
\text { Open systems are not vacuums } \\
\text { No vacuums result in no } \\
\text { motion }\end{array}$ & $\begin{array}{l}\text { Connecting to one straw } \\
\text { case } \\
\text { Chaining }\end{array}$ \\
\hline
\end{tabular}

for example, when analyzing a manometer. Last, a few students used the unexpected lighter is faster resource (which we saw also in the changing gas discussion; see Table V) explains why the air moves up the straw faster than the water. This was a delightful surprise to have students explain parts of the phenomena that we had ourselves ignored.

We note that some of these resources have more internal structure than others. For example, "no vacuums result in no motion" is composed of "vacuums create pressure differences" and "pressure differences result in motion." Internal structure is expected within the resources framework because resources that are used together frequently can become compiled into a new single resource [68]. Given our data, we cannot claim that all of our students could unpack the compiled resources in a normative way, though we have seen that most of our students did improve their understanding of vacuums [58].

In Table $\mathrm{X}$ we list the complete answers by several students to give evidence of how we recognized signs of in-the-moment productivity. The main evidence of in-themoment productivity in these answers is chaining. The full chain is quite long (see Table VII) but all students chained at least two ideas together.

We recognized chaining by verbal explanations of why something happens, reasoning from entities, and their properties and activities. In Ari's answer, he identified entities (the straw on the outside) and activities (is sucking up air) and changes that occur because of these activities (equalizing the pressure and then, not allowing liquid to be pushed up). All of the students chained by using ideas of either pressure differences or forces. None used nonmechanistic reasoning, such as the teleological argument that vacuums want to be filled. Also, since there are no obvious equations to appeal to for this problem, we did not see causal arguments based on equations alone as we saw in the changing gas problem.

As Hammer points out, student responses may not be normative, but still show progress. Jill does make an error Table X, but we judge her work to be productive. She identified entities ("pressure in the straw in the liquid") and properties ("is greater than the [pressure] of the straw in air") and consequences ("the straw in air will be the only one to take in anything"). She did not realize that the pressure is the same at the top of both straws, but she was aware that pressure differences result in motion. Possibly she has noticed a contradiction that most others have failed to notice (that the air moves upward but the liquid does not) and made an attempt to explain that activity.

Another sign of productivity was an explicit connection to the single straw case. Mary compared and contrasted this case to the case where water moved up the straw, and was 
able to chain together ideas to explain why water did not move up in the two straw case.

An unexpected sign of productivity was use of an analogy. Three students made an analogy between the mouth and a box. This initially surprising connection was explained by one student who noted that a box (at lower than atmospheric pressure and connected to a manometer) was in the previous problem on the homework. The analogy was quite apt and perhaps helped students think about the problem by simplifying the role and structure of the mouth and lungs. Because students could have worked together on the homework, we cannot be sure that these three uses were independent of each other.

\section{Assessment of intervention}

An analysis based on resources and in-the-moment productivity backed up our initial impression that students did well on this problem. The answers displayed a variety of resources, an unexpected resource (open systems are not vacuums), and unexpected attention to detail (why does the air move up but the water does not). The understanding of motion of liquid up a single straw was an important resource for students in this problem, as it provided a contrasting example. The open systems are not vacuums resource allowed the students to differentiate this case from the single straw case. All students were able to construct at least one chain based on entities, activities, and properties. Three students used an unexpected analogy with a box in the previous problem. We conclude that this is a question that can generate rich student thinking and engaged discussions.

This question could be enhanced by asking for labeled sketches (to allow students to identify the different pressure regions), and making it part of in-class group work to bring together the cognitive resources of several students to make sense of this challenging problem. This question is a good candidate for inviting student engagement because it problematizes a familiar situation (drinking up one straw); the familiarity allows students to focus on entities and their properties and activities rather than spending time conceptualizing the statement of the problem itself. A final advantage is that this situation is not described by any familiar equations, hence resorting to recursive plug and chug is not an option [66].

\section{DISCUSSION AND CONCLUSION}

We have detailed the affordances of the resources framework in designing, assessing, and refining two interventions on pressure in fluids: The first, a tutorial on the changing gas problem and the second, a homework assignment on the two straw problem.

We wrote these interventions to prime and refine conceptual resources on which students could build their understanding. The resources used by students included intuitive resources (e.g., lighter is faster and open systems are not vacuums), bits of normative science (e.g., the ideal gas law), and resources that connect intuitive understanding to mathematics (e.g., no dependence symbolic form). The resources that we chose to prime were based on the literature, initial interviews, and work of our collaborators [24]. The resources framework encourages instructors to be attentive to the resources that students bring to the classroom.

Despite both activities involving the discussion of pressure in fluids, the contexts of the two problems were quite different and we found that the activated resources were also quite different (see Tables IV and IX), as expected within the resources framework.

Reasoning even about a single question can also be complex. Frank et al. [9] show that even a simple kinematics question can activate several conflicting resources that need to be coordinated, refined, and integrated. In the changing gas problem, we knew that the reasoning was complicated and so we asked a follow up conflicting contentions task to give students another opportunity to revisit the question, possibly with a different set of activated resources given the different cueing in the problem. With the double straw problem, the similarity to the single straw problem activated several useful resources, but the surprising failure of two straws to draw up fluid then likely sent students in search of more cognitive resources to explain the difference. By framing and reframing a difficult question, a wider variety of resources can be recruited, and coordinating these can lead to rich, productive discussions.

To assess our interventions, we looked for signs of inthe-moment productivity instead of textbook correctness. The main evidence for this was mechanistic chaining, starting with entities and their properties and activities (i.e., molecules colliding with walls or columns of fluid and pressure), to draw conclusions about consequences. An analogy (mouth as a box) and noticing of confusions ("which matters more?") were two other signs of productivity. We were also able to identify missing resources (e.g., strength of collision depends on mass and velocity) and unexpected resources (e.g., open systems are not vacuums) that could be leveraged more fully in future iterations of the interventions. Last, we identified the ideal gas law as a barrier to in-the-moment productivity: some students used this equation in place of mechanistic chaining to draw conclusions about pressure in the ideal gas law tutorial. The resources framework suggests that we not rush students to reach the correct answer because it takes time to build a normative understanding from initial ideas. By focusing on productivity instead of correctness, instructors can recognize and encourage progress at all stages of understanding.

In addition to helping identify student reasoning with regarding to productiveness and "making progress," in-themoment productivity can also help educators decide when and how to intervene during student discussions. Hammer notes "teachers are constantly making choices, whether implicitly or explicitly, of how to perceive what their 
students are doing and how to respond to those perceptions" [69]. He urges us to listen to student talk in more ways than evaluating for textbook correctness, looking instead for progress and resources in their many guises. As an example of how focus on textbook correctness leads to undesirable effects, Russ et al. [54] describe a classroom interaction where insistence on correctness quickly changed a student from mechanistic reasoning to hunting for (poorly understood) scientific terms. Conversely, Scherr and Robertson [51] point out the initial focus on productivity instead of correctness can "promote both student agency and student conceptual progress," and that normative reasoning can evolve through "negotiation and reconciliation."

Our work on pressure in fluids confirms the value of the resources framework described in the literature $[5-7,12,48]$. While the details of the resources primed and refined will vary with physics context, the habits of looking for those resources in the literature and student talk, being open to the need for a wide variety of resources and different resources in each context, and focusing on productivity instead of text book correctness are all useful pedagogical tools.

This approach fails if cognitive resources are scarce, but there is evidence that this is not the case. We have seen in our own data that students have the resources to reason about pressure in fluids. In addition, student conceptual resources have been identified in several challenging topics within physics and mathematics: entropy [70], sound waves [12], energy [8,46,71], electric fields [72], gravity [73], differentials [74], and connecting meaning and mathematics [11].

Our next steps in this program will be developing a tutorial on the challenging and unexplored (from a PER perspective) topic of viscosity within the resources framework. We know from initial investigations that there are several conceptual resources that could be used productively in different contexts: intuitive notions of stickiness and everyday experiences with fluids, understanding of friction, and familiarity from chemistry with weak intermolecular forces. We will investigate which of these resources are useful in which contexts, and if other resources are need to be productive in reasoning mechanistically about viscous fluids.

One of the big questions for us was the appropriate role of the microscopic point of view in student thinking. Despite concerns from Kautz et al. [26] about the use of the microscopic viewpoint in discussing ideal gases, we have evidence of success of the microscopic viewpoint in improving student understanding about vacuums and therefore embraced that perspective. However, later in curriculum development of the motion up a straw, we noticed that the microscopic viewpoint was not used by the students and we realized that it was too cumbersome for that system. Russ et al. [49] also point out that sometimes the microscopic view is useful for mechanistic reasoning and sometimes not, depending on the scale of the entities in the problem. So we return to the original conflict in Sec. III to note that the microscopic viewpoint should certainly be considered if it holds the promise of allowing students to reason mechanistically and economically, and if it allows some ideas (e.g., pressure, vacuum) to become less mysterious and more concrete. While these considerations held true for the discussion of the properties of ideal gases, the behavior of the double straw system required a different approach at the macroscopic level, where the students focused on vacuums, air pressure, and columns of air and water.

\section{ACKNOWLEDGMENTS}

The authors gratefully acknowledge enlightening conversations with James Vesenka, Katherine Misaiko, Elizabeth Whitmore, Rosemary Russ, David Hammer, Michael Wittmann, and Benedikt Harrer. The work was supported by the National Science Foundation under Grant No. 1044211.
[1] R. E. Scherr, Modeling student thinking: An example from special relativity, Am. J. Phys. 75, 272 (2007).

[2] M. E. Loverude, C. H. Kautz, and P. R. L. Heron, Helping students develop an understanding of archimedes principle. i. research on student understanding, Am. J. Phys. 71, 1178 (2003).

[3] P. R. L. Heron, M. E. Loverude, P. S. Shaffer, and L. C. McDermott, Helping students develop an understanding of Archimedes principle. ii. development of research-based instructional materials, Am. J. Phys. 71, 1188 (2003).

[4] M. E. Loverude, P. R. L. Heron, and C. H. Kautz, Identifying and addressing student difficulties with hydrostatic pressure, Am. J. Phys. 78, 75 (2010).
[5] E. F. Redish and D. Hammer, Reinventing college physics for biologists: Explicating an epistemological curriculum, Am. J. Phys. 77, 629 (2009).

[6] E. F. Redish, Oersted lecture 2013: How should we think about how our students think?, Am. J. Phys. 82, 537 (2014).

[7] D. Hammer, Student resources for learning introductory physics, Am. J. Phys. 68, S52 (2000).

[8] H. C. Sabo, L. M. Goodhew, and A. D. Robertson, University student conceptual resources for understanding energy, Phys. Rev. ST Phys. Educ. Res. 12, 010126 (2016).

[9] B. W. Frank, S. E. Kanim, and L. S. Gomez, Accounting for variability in student responses to motion 
questions, Phys. Rev. ST Phys. Educ. Res. 4, 020102 (2008).

[10] D. Hammer and A. Elby, Tapping epistemological resources for learning physics, J. Learn. Sci. 12, 53 (2003).

[11] E. Redish and E. Kuo, Language of physics, language of math: Disciplinary culture and dynamic epistemology, Sci. Educ. 24, 561 (2015).

[12] M. C. Wittmann, R. N. Sternberg, and E. F. Redish, Understanding and affecting student reasoning about sound waves, Int. J. Sci. Educ. 25, 991 (2003).

[13] D. C. Meredith and J. A. Bolker, Rounding off the cow: Challenges and successes in an interdisciplinary physics course for life science students, Am. J. Phys. 80, 913 (2012).

[14] Committee on Undergraduate Biology Education to Prepare Research Scientists for the 21st Century, Bio 2010: Transforming Undergraduate Education for Future Research Biologists (The National Academies Press, Washington, DC, 2003).

[15] Vision and change 2011 report, http://visionandchange .org/, accessed: September 3, 2014.

[16] AAMC-HHMI Committee, Scientific Foundations for Future Physicians (American Association of Medical Colleges, Washington, DC, 2009).

[17] C. H. Crouch, R. Hilborn, S. A. Kane, T. McKay, and M. Reeves, Physics for future physicians and life scientists: A moment of opportunity, APS news, Vol. 19, p. 8, http:// www.aps.org/publications/apsnews/201003/upload/ March2010.pdf.

[18] D. C. Meredith and E. F. Redish, Reinventing physics for life science majors, Phys. Today 66, 38 (2013).

[19] Conference on Introductory Physics for the Life Science Report (AAPT, College Park, MD, 2015), http://www .compadre.org/IPLS/documents/IPLS-Final-Report.pdf.

[20] Special issue integrating physics and biology education, Cell Bio. Educ. 2 (2013), http://www.lifescied.org/content/ 12/2.toc.

[21] M. Sabella and M. Lang Research and education at the crossroads of biology and physics, Am. J. Phys. 82, 365 (2014).

[22] S. Vogel, Life in Moving Fluids (Princeton University Press, Princeton, NJ, 1983).

[23] M. W. Denny, Air and Water: The Biology and Physics of Life's Media (Princeton University Press, Princeton, NJ, 1993).

[24] K. Misaiko and J. Vesenka, Connecting the dots: Links between kinetic theory and Bernoulli's principle, in Englehardt et al., [25] pp. 257-260, DOI: 10.1119/ perc.2013.pr.052.

[25] Proceedings of the Physics Education Research Conference 2013, Portland, OR, edited by P. Englehardt, A. Churukian, and D. L. Jones (AIP, New York, 2013).

[26] C. H. Kautz, P. R. L. Heron, M. E. Loverude, and L. C. Mcdermott, Student understanding of the ideal gas law, part i: A macroscopic perspective, Am. J. Phys. 73, 1055 (2005).

[27] C. H. Kautz, P. R. L. Heron, P. S. Shaffer, and L. C. Mcdermott, Student understanding of the ideal gas law, part ii: A microscopic perspective, Am. J. Phys. 73, 1064 (2005).
[28] A. D. Robertson and P. S. Shaffer, University student and K-12 teacher reasoning about the basic tenets of kinetic-molecular theory, part i: Volume of an ideal gas, Am. J. Phys. 81, 303 (2013).

[29] M.E. Loverude, A research-based interactive lecture demonstration on sinking and floating, Am. J. Phys. 77, 897 (2009).

[30] N. Gillespie, Ph.D. thesis, University of California, Berkeley, 2004.

[31] R. W. Chabay and B. A. Sherwood, Bringing atoms into first-year physics, Am. J. Phys. 67, 1045 (1999).

[32] R. W. Chabay and B. A. Sherwood, Matter and Interactions (John Wiley and Sons, New York, 2011).

[33] D. L. Gabel, K. V. Samuel, and D. Hunn, Understanding the particulate nature of matter, J. Chem. Educ. 64, 695 (1987).

[34] B. T. Hwang, Students' conceptual representations of gas volume in relation to particulate model of matter, in Proceedings of the 1995 Annual NARST Meeting, San Francisco, CA (NARST, Reston. VA, 1995).

[35] Z. D. Kirbulut and M. E. Beeth, Representations of fundamental chemistry concepts in relation to the particulate nature of matter, Int. J. Educ. Math. Sci. Technol. 1, 96 (2013).

[36] N. Becker, C. Rasmussen, G. Sweeney, M. Wawro, M. Towns, and R. Cole, Reasoning using particulate nature of matter: An example of a sociochemical norm in a university-level physical chemistry class, Chem. Educ. Res. Pract. 14, 81 (2013).

[37] C. A. Bridle and E. J. Yezierski, Evidence for the effectiveness of inquiry-based, particulate-level instruction on conceptions of the particulate nature of matter, J. Chem. Educ. 89, 192 (2012).

[38] E. D. Corpuz and S. Rebello, Investigating students' mental models and knowledge construction of microscopic friction. i. implications for curriculum design and development, Phys. Rev. ST Phys. Educ. Res. 7, 020102 (2011).

[39] E. D. Corpuz and S. Rebello, Investigating students' mental models and knowledge construction of microscopic friction. ii. implications for curriculum design and development, Phys. Rev. ST Phys. Educ. Res. 7, 020103 (2011).

[40] A. A. diSessa, Toward an epistemology of physics, Cognit. Instr. 10, 105 (1993).

[41] B. L. Sherin, How students understand physics equations, Cognit. Instr. 19, 479 (2001).

[42] K. E. Black and M. C. Wittmann, Mathematical actions as procedural resources: An example from the separation of variables, Phys. Rev. ST Phys. Educ. Res. 11, 020114 (2015).

[43] B. Harrer, Ph.D. thesis, University of Maine, Orono, 2013.

[44] E. C. Sayre and M. C. Wittmann, Plasticity of intermediate mechanics students coordinate system choice, Phys. Rev. ST Phys. Educ. Res. 4, 020105 (2008).

[45] D. Hammer, A. Elby, R. E. Scherr, and E. F. Redish, Transfer of Learning: Research and Perspectives (Current Perspectives on Cognition, Learning, and Instruction) (Information Age Publishing, Greenwich, CT, 2005), pp. $89-120$ 
[46] B. W. Harrer, V. J. Flood, and M. C. Wittmann, Productive resources in students' ideas about energy: An alternative analysis of watts' original interview transcripts, Phys. Rev. ST Phys. Educ. Res. 9, 023101 (2013).

[47] R.E. Scherr, Gesture analysis for physics education researchers, Phys. Rev. ST Phys. Educ. Res. 4, 010101 (2008).

[48] A. Elby Helping physics students learn how to learn, Am. J. Phys. 69, S54 (2001).

[49] R. S. Russ, R. E. Scherr, D. Hammer, and J. Mikeska, Recognizing mechanistic reasoning in student scientific inquiry: A framework for discourse analysis developed from philosophy of science, Sci. Educ. 92, 499 (2008).

[50] R. A. Engle and F. R. Conant, Guiding principles for fostering productive discplinary engagement: Explaining an emergent argument in a community of learners classroom, Cognit. Instr. 20, 399 (2002).

[51] R. E. Scherr and A. D. Robertson, Productivity of "collisions generate heat" for reconciling an energy model with mechanistic reasoning: A case study, Phys. Rev. ST Phys. Educ. Res. 11, 010111 (2015).

[52] W. K. Adams, K. K. Perkins, N. S. Podolefsky, M. Dubson, N. D. Finkelstein, and C. E. Wieman, New instrument for measuring student beliefs about physics and learning physics: The Colorado Learning Attitudes about Science Survey, Phys. Rev. ST Phys. Educ. Res. 2, 010101 (2006).

[53] L. Lising and A. Elby, The impact of epistemology on learning: A case study from introductory physics, Am. J. Phys. 73, 372 (2005).

[54] R. S. Russ, R. E. Scherr, D. Hammer, and P. Hutchinson, Making classroom assessment more accountable to scientific reasoning: A case for attending to mechanistic thinking, Sci. Educ. 93, 875 (2009).

[55] T. I. Smith and M. C. Wittmann, Applying a resources framework to analysis of the force and motion concept evaluation, Phys. Rev. ST Phys. Educ. Res. 4, 020101 (2008).

[56] E. C. Sayre, S. V. Franklin, S. Dymek, J. Clark, and Y. Sun, Learning, retention, and forgetting of Newton's third law throughout university physics, Phys. Rev. ST Phys. Educ. Res. 8, 010116 (2012).

[57] See Supplemental Material at http://link.aps.org/ supplemental/10.1103/PhysRevPhysEducRes.13.010125 for the pencil and paper tutorials on pressure in ideal gases and fluid flow in pipes that we developed as part of this grant.

[58] D. C. Meredith and D. E. Young, Teaching fluids to IPLS students from a microscopic viewpoint, in Proceedings of the Physics Education Research Conference 2013, Portland, OR (2013) [25], pp. 373-376, DOI: 10.1119/ perc.2013.pr.081.

[59] J. Corbin and A. Strauss, Basics of Qualitative Research: Techniques and Procedures for Developing Grounded Theory (Sage Publications, Los Angeles, CA, 2008).

[60] K. Charmaz, Constructing Grounded Theory (Sage Publications, Thousand Oaks, CA, 2006).

[61] http://blogs.howstuffworks.com/transcript/how-does-atraffic-light-detect-cars.htm, checked December 2015.
[62] R. Warner, Applied Statistics, 2nd ed. (Sage Publications, Los Angeles, 2013), Sec. 21.3 on Empirical Examples of Reliability Assessment.

[63] In the original tutorial we incorrectly used, "force of collision" rather than the correct "impulse of collision" or the less precise but also less opaque "strength of collision" when talking about the beach balls, but used strength of collision when talking about the gas. We assert that this error does not weaken our claims. First, the students used both the terms "force" and "energy" of collision, never wrote down equations in this context, but did note that both depended directly on mass and velocity as impulse does. Second, in all cases students used the ideal gas law and no other equation, to conclude that the decrease of the mass and the increase of the velocity exactly compensated to give no change in pressure.

[64] This is close to the notion of balancing, but not quite the same. The balancing symbolic form [41] referred to balancing of forces. Abstract balancing [66] "involves the general notion that two unspecified influences can be in a state of equilibrium," such as balancing competing needs or competing views. In our case there is no sense of equilibrium, so compensation seems a more accurate description.

[65] While the resources "lighter is faster" and "heavier is slower" are two sides of the same coin. We have decided to identify two distinct resources because we might find later that their activation and connections are different. The same might also be said for the double straw resources "no pressure differences result in no motion" and "pressure differences result in motion."

[66] J. Tuminaro and E. F. Redish, Elements of a cognitive model of physics problem solving: Epistemic games, Phys. Rev. ST Phys. Educ. Res. 3, 020101 (2007).

[67] R. D. Knight, B. Jones, and S. Field, College Physics: A Strategic Approach (Addison Wesley, Boston, 2010).

[68] E. F. Redish, R. E. Scherr, and J. Tuminaro, Reverseengineering the solution of a "simple" physics problem: Why learning physics is harder than it looks, Phys. Teach. 44, 293 (2006).

[69] D. Hammer, More than misconceptions: Multiple perspectives on student knowledge and reasoning, and an appropriate role for education research, Am. J. Phys. 64, 1316 (1996).

[70] M. Loverude, Identifying student resources in reasoning about entropy and the approach to thermal equilibrium, Phys. Rev. ST Phys. Educ. Res. 11, 020118 (2015).

[71] E. Brewe, Energy as a substancelike quantity that flows: Theoretical considerations and pedagogical consequences, Phys. Rev. ST Phys. Educ. Res. 7, 020106 (2011).

[72] Y. Cao and B. M. Brizuela, High school students representations and understandings of electric fields, Phys. Rev. Phys. Educ. Res. 12, 020102 (2016).

[73] A. Gupta, A. Elby, and L. D. Conlin, How substancebased ontologies for gravity can be productive: A case study, Phys. Rev. ST Phys. Educ. Res. 10, 010113 (2014).

[74] D. Hu and N. Sanjay Rebello, Understanding student use of differentials in physics integration problems, Phys. Rev. ST Phys. Educ. Res. 9, 020108 (2013). 